\title{
A triste trama da identificação em Luto e melancolia
}

\section{The sad weft of the identification in Mourning and melancholia}

\author{
Rafael Lopes do Valle \\ Graduação em andamento em Filosofia (2014). Universidade Federal de São Carlos - UFSCar - Centro \\ de Educação e Ciências Humanas, Departamento de Filosofia, São Carlos, SP - Brasil.
}

Resumo: O presente artigo tem por objetivo compreender a melancolia através da trama da identificação que opera por trás desta afecção, partindo de uma análise de Luto e melancolia (1917). Neste ensaio metapsicológico, Freud busca esclarecer a essência da melancolia comparando-a com o afeto normal do luto. Ambas apresentam quase que o mesmo quadro sintomático, com a diferença de um elemento que encontramos apenas no melancólico: o rebaixamento de sua autoestima, que se expressa em autorrecriminações e autoinsultos. Por meio deste característico elemento, veremos que o conflito que se opera no Eu do melancólico pode ser posto à luz pela compreensão da trama da identificação, que amarra os principais elementos da melancolia.

Palavras-chave: Freud; ideal do Eu; identificação; melancolia; metapsicologia.

\begin{abstract}
The present article aims to understand the melancholia through the weft of the identification that operates behind this affection, starting from an analysis of Mourning and melancholia (1917). In this metapsychological essay, Freud seeks to clarify the essence of melancholia by comparing it with the normal affect of mourning. Both present almost the same symptoms, with the difference of an element that we find only in the melancholic: the lowering of their self-esteem, which is expressed in self-criticisms and self-insults. By means of this characteristic element, we will see that the conflict that operates in the melancholic ego can be brought to light by the understanding of the weft of the identification, which ties the main elements of melancholia.
\end{abstract}

Keywords: Freud; ego ideal; identification; melancholia; metapsychology. 


\section{A identificação}

Luto e melancolia [Trauer und Melancholie] (1917) é mais do que um estudo analítico de patologia. Laplanche (1987, p. 288) destaca que: “Este texto situa-se no contexto de importantes modificações da teoria freudiana". O psicanalista francês e outros autores ressaltam a importância deste artigo para a concepção da malha teórica freudiana da chamada "segunda tópica". O elemento que se destaca nessa constelação conceitual da melancolia é a identificação [Identifizierung]. Segundo Simanke, o conceito de identificação recebe neste ensaio metapsicológico "o seu primeiro tratamento teórico mais aprofundado, para retornar depois em Psicologia das massas e análise do Eu (1921)" (SIMANKE, 1994, p. 161). Além disso, aponta que: “O início de um estudo sistemático da identificação é, talvez, a maior contribuição teórica presente em Luto e melancolia" (SIMANKE, 1994, p. 163).

Ora, o que seria a identificação para Freud? "A psicanálise conhece a identificação como a mais antiga ligação afetiva a uma pessoa" (FREUD, 2011b [1921], p. 60). De forma sucinta, a identificação é a incorporação de um objeto que levaria a uma modificação do Eu. "Comporta-se como um derivado da primeira fase, a fase oral da organização da libido, na qual o indivíduo incorporou, comendo, o objeto desejado e estimado, e assim o aniquilou enquanto objeto" (FREUD, 2011b [1921], p. 61). Neste ato canibal, que se processa no "nível da fantasia" (FLORENCE, 1994, p. 128), o objeto é devorado e parte dele é integrada ao Eu. É através de um único ato que o objeto é aniquilado e, ao mesmo tempo, conservado no bojo do Eu, expressando assim a ambivalência (odiar-aniquilar/amar-conservar) desse mecanismo.

A identificação com o objeto amado acaba se tornando um substituto da ligação libidinal, conservando a relação amorosa com o objeto. Assim, o vínculo do Eu com o objeto subsistirá mesmo com a ausência deste, conforme veremos no caso da perda na melancolia. A identificação seria o fantasma do objeto perdido a assombrar o melancólico. Ao se referir à substituição do amor objetal pela identificação, Freud (2011a [1917] ${ }^{1}$, p. 63) nos diz que ela corresponde "naturalmente à regressão de um tipo de escolha de objeto para o narcisismo originário". A identificação toma o lugar da escolha objetal, direcionando a libido para si, de forma que a escolha objetal é regredida para o Eu. O Eu passa então a ser o depositório da libido, assim como fora no "narcisismo originário" [ursprünglich Narzissmus]².

Incorporado o objeto, o Eu modifica-se pela alteridade, por aquilo que Assoun (1996) denomina de "outro Eu estranho", e esse outro Eu passa a ocupar o lugar do próprio Eu. Vemos que o que se opera nessa dialética do Eu com objeto é o desejo de tornar-se o outro. Há uma distinção cara a Freud entre ter e ser, entre a escolha objetal e a identificação ${ }^{3}$. Notemos que a identificação não se resume à presença do objeto, mas refere-se também à efetividade deste no sujeito, a ponto de ele dizer: "eu sou o outro".

O mecanismo da identificação é abordado no artigo sobre a melancolia de forma sucinta e unilateral, apenas no que tange à afecção melancólica. Todavia, já podemos ver uma mudança conceitual de tal mecanismo. A identificação, nos escritos anteriores, referia-se ao mecanismo de formação do sintoma histérico. Sobre a identificação histérica devemos considerar que ela não é mera imitação, ela é a apropriação de

\footnotetext{
${ }^{1}$ A partir daqui, faremos referência a Luto e melancolia pela sigla L\&M.

${ }^{2}$ Sendo conceitualmente o mesmo que narcisismo primário [primärer Narzissmus], cf. CARONE, 2011, p. 62.

${ }^{3}$ Essa distinção pode ser melhor observada na pré-história do complexo de Édipo. Tomemos o exemplo do caso masculino. O garoto exibe uma aspiração de ser como o pai, de tornar-se o pai e de ocupar o lugar dele em todas as situações. Isso inclui também ocupar o lugar do pai no que se refere à relação com a mãe. Assim, o garoto toma a mãe como objeto de amor. Notamos então duas ligações psicológicas distintas: "com a mãe, um investimento objetal direto; com o pai, uma identificação" (FREUD, 2011b [1921], p. 61).
} 
qualidades, e até de sintomas, do objeto da rivalidade ou do amor. A identificação histérica, segundo Florence, revela a falha na elaboração do abandono do objeto edipiano, "conservando a relação incestuosa no inconsciente e fazendo o sujeito sofrer" (FLORENCE, 1994, p. 130).

Em Uma recordação de infância de Leonardo da Vinci (1910), através da interpretação da homossexualidade e as considerações sobre a escolha objetal, a identificação é posta sob uma nova luz. Mas é após a introdução ao conceito de narcisismo, no artigo de 1914, que a identificação ganha corpo, passando a ser objeto de um tratamento muito mais elaborado e aprofundado. Sendo assim, de acordo com Monzani (2014, p. 238), o conceito de identificação passa a ser encarado como um dos mecanismos fundamentais na constituição e, sobretudo, na remodelação do Eu. Nas palavras do comentador:

Quer dizer, a partir dessa época, a identificação não é somente um mecanismo psíquico que esclarece certos fenômenos patológicos, na histeria sobretudo, mas passa a ser também um modo de constituição do Eu“ "normal” (MONZANI, 2014, p. 238).

Nos artigos ulteriores, como Psicologia das massas e análise do Eu (1921) e O Eu e o Isso (1923), esse mecanismo vai ganhar cada vez mais importância, permitindo a compreensão da pré-história do complexo de Édipo e da formação de uma massa.

\section{A melancolia e a sua comparação com o luto}

No ensaio metapsicológico de 1917, Freud busca esclarecer a essência da melancolia, perturbação psíquica de difícil definição conceitual, comparando-a com o afeto normal do luto. O luto consiste na reação "à perda de uma pessoa querida ou de uma abstração que esteja no lugar dela, como pátria, liberdade, ideal etc." (L\&M, p. 47). O enlutado, enquanto dolorosamente processa essa perda, atividade denominada de trabalho realizado pelo luto, entristece-se profundamente, perde o interesse pelo mundo externo, não consegue investir libidinalmente um novo objeto e evita realizar qualquer atividade. Todavia, o luto não é considerado um estado patológico, ele é uma reação normal, apesar de afetar a conduta da vida cotidiana. Ninguém procura um médico por estar de luto. Sabemos que, ao final do trabalho realizado pelo luto, o indivíduo terá superado a perda do objeto e estará apto a seguir adiante. Isso acontece porque a superação da morte é uma imposição do princípio de realidade. "O normal é que vença o respeito à realidade" (L\&M, p. 49). O objeto amado já não existe mais, porém, a superação da morte não se dá imediatamente, leva-se tempo, ela ocorre pouco a pouco, a fim de prolongar psicologicamente a existência do objeto. "Uma a uma, as lembranças e expectativas pelas quais a libido se ligava ao objeto são focalizadas e superinvestidas e nelas se realiza o desligamento da libido" (L\&M, p. 49). Assim, o enlutado obtém uma satisfação necrófila alucinatória ao investir todas as lembranças remanescentes enquanto, progressivamente, os laços afetivos com o objeto vão se desfazendo.

A melancolia, por sua vez, também é a reação à perda de um objeto amado e apresenta quase que o mesmo quadro sintomático que o luto. Contudo, a perda do melancólico é de natureza mais ideal, ou seja, diferentemente do luto, o objeto não necessariamente morreu. O objeto foi perdido ou abandonado devido a uma ofensa ou frustração. Além disso, tudo se passa inconscientemente. Freud observa que "não podemos discernir com clareza o que se perdeu e com razão podemos supor que o doente também não é capaz de compreender conscientemente o que ele perdeu"

${ }^{4}$ Cf. a nota seguinte. 
(L\&M, p. 51). O melancólico até pode saber quem ele perdeu, mas não sabe o que perdeu no objeto.

Ademais, a melancolia ainda apresenta um elemento que não se encontra no quadro sintomático do luto: o rebaixamento da autoestima [Selbstgefühl], ou seja, o empobrecimento do "sentimento de si", "que se expressa em autorrecriminações e autoinsultos, chegando até a expectativa delirante de punição" (L\&M, p. 47). Marilene Carone nos convida a observar o jogo de palavras utilizado pelo austríaco. Segundo a tradutora e psicanalista (2011, p. 46, nota 3), com Selbstgefühl começa em Luto e melancolia uma série de termos com o prefixo selbst, que geralmente é traduzido para o português por auto. Dentre esses termos, temos autorrecriminação, autoinsulto, autocrítica, autodepreciação, autoavaliação, autoacusação, autotormento, autopunição e, por fim, suicídio, tradução de Selbstmord, literalmente autoassassinato. Marilene Carone observa ainda que:

Essa profusão de termos com selbst certamente encontra seu sentido mais profundo na articulação teórica do próprio texto e reflete a importância desse movimento de retorno à própria pessoa, descritos em Pulsões e destinos da pulsão (Triebe und Triebschicksale, 1915) como o segundo destino pulsional. (CARONE, 2011, p. 46, nota 3)

Destarte, essas observações sobre a perda da autoestima levam Freud a concluir que: "No luto é o mundo que se tornou pobre e vazio; na melancolia é o próprio $\mathrm{Eu}^{5 "}$ (L\&M, p. 53). Vemos, por conseguinte, que há um empobrecimento do Eu ao se abandonar o objeto. Tudo funciona como se a perda do objeto fosse sentida como perda de aspectos do Eu. O melancólico descreve seu Eu como indigno, incapaz e moralmente desprezível. A partir disso, podemos notar que o melancólico não se sente acanhado em fazer suas autorrecriminações perante outras pessoas. "Humilha-se perante os demais e tem pena dos seus por estarem eles ligados a uma pessoa tão indigna" (L\&M, p. 53). Há no melancólico uma tendência a se comunicar, a se desnudar, na qual ele encontra satisfação. O psicanalista aponta, então, uma contradição: "Segundo a analogia com o luto, deveríamos concluir que ele sofreu uma perda no objeto; de suas afirmações surge uma perda em seu Eu" (L\&M, p. 53).

Apesar de todas as autoacusações de inferioridade, vê-se que não há qualquer correspondência entre o montante de autodegradação e sua equivalência com a real justificativa. Se ouvirmos atentamente os autoinsultos do enfermo, perceberemos que eles não se adéquam inteiramente à sua pessoa. As ofensas referem-se, antes, ao objeto perdido. Eis que emerge o conceito de identificação: as ofensas revelam que o Eu confunde-se com o objeto perdido. Neste sentido, o Eu se identificou com tal objeto, ou seja, ele foi incorporado e assimilado pelo Eu.

Resumindo o trajeto da perda: "Houve uma escolha de objeto, uma ligação da libido a uma pessoa determinada; graças à influência de uma ofensa real ou decepção por parte da pessoa amada, essa relação de objeto ficou abalada" (L\&M, p. 61). Contudo, após a perda do objeto, a reação não foi a normal, um novo objeto não foi elencado. O Eu não quis abandoná-lo mesmo após a frustração. A ligação libidinal com o objeto foi frágil, a ponto de não sustentar uma frustração, entretanto, ela não foi renunciada. $\mathrm{O}$ vínculo com o objeto foi mantido no interior do Eu por meio da identificação devido a uma forte fixação. Então, em vez de se descolar para outro objeto, a libido livre é retraída ao Eu, ao qual aderira tão fortemente numa etapa infantil. O melancólico, ademais, obtém a satisfação com o objeto perdido através desse traço remanescente. Assim entende Freud quando escreve:

\footnotetext{
${ }^{5}$ Marilene Carone, tradutora da edição de Luto e melancolia que estamos utilizando, traduz Ich, pronome pessoal da primeira pessoa no singular da língua alemã, pelo termo latinizado ego. Diferentemente dela, seguimos aqueles que preferem se ater à letra de Freud, optando pelo emprego do pronome pessoal equivalente em português: Eu (com o e em maiúsculo). Assim, para manter a uniformidade do texto, faremos a mudança de ego para Eu conforme nos for conveniente, e isso vale também para as outras obras da nossa bibliografia.
} 
A identificação narcísica com o objeto se torna então um substituto do investimento amoroso e disso resulta que, apesar do conflito, a relação com a pessoa amada não precisa ser abandonada. (L\&M, p. 63)

\section{A escolha narcísica e o ideal do Eu}

O mecanismo da identificação nos leva a observar que, na melancolia, a escolha objetal foi do tipo narcísica. A identificação, diz-nos o vienense, "é a etapa preliminar da escolha de objeto, e é a primeira modalidade, ambivalente na sua expressão, pela qual o Eu distingue um objeto" (L\&M, p. 63). O sujeito, primeiramente, identifica-se com um objeto, querendo sê-lo, e, posteriormente, elenca outro objeto para se ter. Todavia, no narcisismo, essa dicotomia ser/ter se conflui. O sujeito narcísico, conforme vemos em Introdução ao narcisismo (1914), elenca um objeto que satisfaça os seus ideais, diferenciando-se da escolha objetal de apoio. Depois do interesse sexual pelo próprio Eu, o narcísico se orienta para um objeto semelhante a ele. Ele pode elencar um objeto que representa (1) aquilo que ele foi, (2) aquilo que ele é ou (3) aquilo que ele gostaria de ser.

Em seguida, o Eu modificado pela identificação passa a ser medido pelo ideal do $\mathrm{Eu}$ [Ichideal], objeto narcisista por excelência cuja função é avaliar as realizações do Eu por seu parâmetro idealizado (MEZAN, 2006, p. 182). O narcísico se comprazerá ao se equiparar aos seus ideais. No artigo de 1914, o médico austríaco concebe que o Eu do bebê, enquanto investido por toda a libido, é ideal. É como se, na amamentação, o seio da mãe fosse incorporado e considerado parte do $\mathrm{Eu}$, de forma que não se distinguem mais Eu e objeto, e todo o mundo externo passa a ser ignorado. O Eu ideal [Idealich] basta a si mesmo, ele representa a posse da perfeição e da completude. A criança encontra-se, então, no estágio do narcisismo primário. Mas, na medida em que o mundo externo passa a ser requisitado, o Eu ideal é abandonado. O Eu, todavia, uma vez que desfrutou do estado de perfeição e completude do narcisismo de sua infância, mostra-se incapaz de renunciar a essa satisfação. $\mathrm{O}$ Eu ideal deve então ser reencontrado. O Eu procurará "readquiri-lo na forma nova de um ideal do Eu. O que ele projeta diante de si como seu ideal é o substituto para o narcisismo perdido da infância, na qual ele era seu próprio ideal" (FREUD, 2010 [1914], p. 40). O amor a si próprio desfrutado na infância é dirigido agora a esse ideal do Eu, herdeiro do Eu ideal.

O ideal do Eu é uma instância autônoma que se separou do resto do Eu, e contém a consciência moral. O Eu passa a ser medido segundo os seus ideais, e, quanto mais idealizados forem esses ideais, maiores serão as exigências do Eu. De acordo com Birman (1993, p. 92): “A instauração de um ideal do Eu introduz justamente uma dialetização entre o Eu e seus ideais, de maneira a inserir uma fenda que rompe com a onipotência narcísica do sujeito". Neste sentido, não sendo mais o próprio Eu o ideal, o Eu estabelece uma dialética com os seus ideais, ele tem de se mostrar à altura deles, e será julgado por isso.

A cisão que ocorre no Eu com a separação de uma parte de si, o ideal do Eu, explicará a contradição entre perda no objeto e perda no Eu. Freud (L\&M, p. 57) destaca que uma parte do Eu se contrapõe à outra, avalia-a criticamente, vigia-a e a toma por objeto. Após a frustração provinda do objeto amado, o sujeito perde toda a idealização construída pela qual media seu Eu. O objeto não está mais à altura do ideal do Eu, e o Eu fica abandonado ao léu. O vazio se instaura e uma fenda na esfera psíquica irrompe. A perda do objeto transforma-se em perda do Eu, perda que se transforma em ferida narcísica. Contudo, como falamos anteriormente, o objeto é mantido no Eu por meio da identificação. A fixação é enorme, e a libido é regredida ao narcisismo. Isto é, a regressão se dá no nível organizacional do Eu. 
Com a regressão da libido, o melancólico continua obtendo sua satisfação através da identificação, substituta do amor objetal. A substituição do amor objetal pela identificação é um mecanismo importante para as afecções narcísicas. Sendo assim, a melancolia é classificada como uma neurose narcísica, ao lado da paranoia e da esquizofrenia 6 .

\section{$\mathrm{O}$ retorno do sadismo ao $\mathrm{Eu}$}

Após a frustração dos ideais, a instância crítica quer se vingar do objeto abandonado por este não ter cumprido com as exigências daquela. Contudo, diz-nos o psicanalista: "A sombra do objeto caiu sobre Eu" (L\&M, p. 61). O Eu é eclipsado pelo objeto, e o espelho passa a refletir a imagem do "outro Eu estranho". O Eu modificado pela identificação é tomado como objeto pela consciência moral e passa a receber todos os agravos. "Assim, a perda do objeto se transformou em perda do Eu e o conflito entre o Eu e a pessoa amada em uma bipartição entre a crítica do Eu e o Eu modificado pela identificação" (L\&M, p. 61).

O quadro clínico da melancolia põe em destaque o desagrado moral com o próprio $\mathrm{Eu}$, acima de outros defeitos. Na medida em que fica elucidado que o Eu sofre no lugar do objeto amado, o médico austríaco pôde compreender por que as ofensas proclamadas em alto e bom som pelo melancólico não se adequavam inteiramente à sua pessoa. Nas palavras de Freud:

Se se ouvir com paciência as múltiplas autoacusações do melancólico, no fim não deixará de ter a impressão de que as mais violentas dentre elas frequentemente se adéquam muito pouco à sua própria pessoa, mas que, com ligeiras modificações, se adéquam a uma outra pessoa, a quem o doente ama, amou ou deveria amar. (L\&M, p. 59)

As autorrecriminações são recriminações contra o objeto perdido que se voltaram contra o próprio Eu. Portanto, "queixar-se é dar queixa" (L\&M, p. 59), no sentido da acusação jurídico-policial. É por isso que o melancólico não se sente acanhado em se expor em sua lamúria. Ele sente a necessidade de se vingar do objeto que o frustrou, encontrando escape para toda essa agressividade na identificação. Compreenderemos as acusações seguindo o exemplo do psicanalista:

A mulher que ruidosamente se apieda do marido por estar ele tão ligado a uma mulher tão incapaz na verdade quer se queixar da incapacidade do marido, em qualquer sentido que esta possa ser entendida. (L\&M, p. 59)

Os destinos da pulsão na melancolia ficam agora elucidados. O amor pelo objeto, que não pôde ser abandonado, é direcionado ao Eu, refugiando-se na identificação, e o seu inverso, o ódio, é dirigido ao objeto que frustra a satisfação sexual, sendo este também representado pelo próprio Eu, como um objeto substitutivo. Neste sentido, "o ódio entra em ação nesse objeto substitutivo, insultando-o, humilhando-o, fazendo-o sofrer e ganhando nesse sofrimento uma satisfação sádica" (L\&M, p. 67). O melancólico, utilizando-se do retorno da agressividade à identificação, satisfaz o seu desejo de vingança. E, como houve a regressão da libido ao Eu, o sadismo converte-se

\footnotetext{
${ }^{6}$ Esta nosografia será revista por Freud após a formulação da segunda tópica. Até 1924, ano de publicação de Neurose e psicose, o psicanalista atribuía a denominação neurose narcísica às afecções que se opunham ao quadro das neuroses de transferência, que compreendem a histeria de angústia, a histeria de conversão e a neurose obsessiva. Segundo Laplanche e Pontalis (2001, p. 313): “Esta oposição é simultaneamente de ordem técnica - dificuldade ou impossibilidade de transferência libidinal - e de ordem teórica - retirada da libido sobre o Eu. Em outras palavras, a relação narcísica prevalece nas estruturas em questão". Após o artigo de 1924, apenas a melancolia será designada sob a rubrica de neurose narcísica, ao passo que as demais afecções serão classificadas como psicoses. Para uma apreciação aprofundada desta questão, conferir A formação da teoria freudiana das psicoses, de Simanke, presente em nossa bibliografia.
} 
em masoquismo, e o autotormento passa a ser indubitavelmente deleitável. Portanto, Freud constata que a libido do melancólico experimentou um duplo destino:

[...] por um lado libidinal regrediu à identificação, mas por outro, sob a influência do conflito de ambivalência, foi remetido de volta à etapa do sadismo, mais próxima desse conflito. (L\&M, p. 69)

Sendo assim, a identificação tece sua trama até mais um elemento da melancolia: a tendência ao suicídio. Elemento, segundo o pai da psicanálise, pelo "qual a melancolia se torna tão interessante - e tão perigosa" (L\&M, p. 69). No início, o suicídio parecia ser inexplicável: no estado primitivo da criança nos deparamos com um grande amor a si próprio (etapa denominada de narcisismo primário); e vemos que a angústia que emerge diante da ameaça à vida corresponderia a uma grande quantidade de libido narcísica sendo liberada. Portanto, é impossível de entender como esse mesmo Eu, tão vinculado à vida e amoroso de si, poderia consentir com sua própria destruição. Mas, depois do estudo sobre a melancolia, torna-se claro que o Eu só pode matar a si próprio se puder, através da regressão da libido objetal para o Eu, tratar a si próprio como um objeto. Neste caso, o suicídio é antes de tudo uma tentativa de homicídio. O melancólico se mata na tentativa de por fim ao seu agressor. Fica evidente ao leitor que, embora o objeto tenha sido perdido, ele se mostra mais poderoso do que o próprio Eu. Destarte, é ao conceber o retorno do sadismo ao Eu que Freud pôde constatar que é por meio da identificação com o objeto que o Eu, sendo "subjugado pelo objeto" (L\&M, p. 69), atenta contra si mesmo.

\section{Considerações finais}

Das três premissas da melancolia, à guisa de conclusão, perda de objeto, ambivalência afetiva e regressão da libido ao $\mathrm{Eu}$, reencontram-se as duas primeiras nas recriminações obsessivas depois de casos de morte, ou seja, no luto. Assim, o fator eficaz na distinção entre luto e melancolia é a regressão da libido ao Eu explicada pelo mecanismo da identificação, que aparece no texto intimamente ligado ao narcisismo e ao ideal do Eu. O conflito que opera no Eu do melancólico é posto à luz pela compreensão da trama deste mecanismo, que amarra os principais elementos dessa doença narcísica. A gênese e a morte do melancólico estão amarradas por essa trama.

A melancolia é tratada brevemente no artigo publicado em 1917, mas inaugura questões fundamentais e corrobora com a compreensão da genealogia do $\mathrm{Eu}$. O Eu se constitui incorporando em si características dos objetos identificados. Assim, o Eu não é fechado em si, como um mônada, mas que deve tolerar a possibilidade de cisão [Spaltung]. O Eu, portanto, não surge em sua completude, mas constitui-se pela alteridade. Somos então remetidos à celebre frase de Freud expressa em $O \mathrm{Eu}$ e o Isso: "o caráter do Eu é um precipitado de objetos abandonados" (1992, p. 31).

Correspondência: Rafael Lopes do Valle. Universidade Federal de São Carlos - UFSCar. Centro de Educação e Ciências Humanas. Departamento de Filosofia. Rodovia Washington Luís. km 235. Monjolinho. São Carlos - SP - Brasil. CEP: 13565-905. E-mail: rafaellopesdovalle@gmail.com.

Apoio financeiro: Nenhum.

Conflito de interesses: Nenhum.

Todos os autores leram e aprovam a versão final submetida à revista Em curso. 


\section{Bibliografia}

ASSOUN, P.-L. Metapsicologia freudiana: uma introdução. Rio de Janeiro: Jorge Zahar Ed., 1996.

BIRMAN, J. Ensaios de teoria psicanalítica, parte 1: metapsicologia, pulsão, linguagem, inconsciente e sexualidade. Rio de Janeiro: Jorge Zahar Ed., 1993.

CARONE, M. Introdução e notas. In: FREUD, S. Luto e melancolia. São Paulo: Cosac Naify, 2011.

FREUD, S. El yo y el ello [1923]. In: Obras completas. Volumen 19. Buenos Aires: Amorrortu, 1992.

Introdução ao narcisismo [1914]. In: Introdução ao narcisismo, ensaios de metapsicologia e outros textos (1914-1916). Tradução de Paulo César de Souza. São Paulo: Companhia das Letras, 2010.

Luto e melancolia [1917]. Tradução, introdução e notas de Marilene Carone. São Paulo: Cosac Naify, 2011a.

Psicologia das massas e análise do Eu [1921]. In: Psicologia das massas e análise do Eu e outros textos (1920-1923). Tradução de Paulo César de Souza. São Paulo: Companhia das Letras, 2011b.

. Uma recordação de infância de Leonardo da Vinci [1910]. In: Observações sobre um caso de neurose obsessiva (o caso do "Homem dos ratos"), Uma recordação de infância de Leonardo da Vinci e outros textos (19091910). Tradução de Paulo César de Souza. São Paulo: Companhia das Letras, 2013.

FLORENCE, J. As Identificações. In: MANNONI, Maud; et al. As identificações na clínica e na teoria psicanalítica. Organização, tradução e prefácio de Ari Roitman. Rio de Janeiro: Relume-Dumará, 1994.

LAPLANCHE, J. Problemáticas I: a angústia. São Paulo: Martins Fontes, 1987.

; PONTALIS, J.-B. Vocabulário de psicanálise. São Paulo: Martins Fontes, 2001.

MEZAN, R. Freud: a trama dos conceitos. $4^{\text {a }}$ edição. São Paulo: Perspectiva, 2006.

MONZANI, L. R. Freud: o movimento de um pensamento. $3^{\text {a }}$ edição. Campinas: UNICAMP, 2014.

SIMANKE, R. T. A formação da teoria freudiana das psicoses. Rio de Janeiro: Editora 34, 1994.

Recebido em: 26/Mai/2018 - Aceito em: 23/Ago/2018. 